2-15-2005

\title{
Aspects of the Morphological Evolution in Thermal Barrier Coatings and the Intrinsic Thermal Mismatch Therein
}

J. Shi

University of Delaware

S. Darzens

University of Delaware

Anette M. Karlsson

Cleveland State University, a.karlsson@csuohio.edu

Follow this and additional works at: https://engagedscholarship.csuohio.edu/enme_facpub

Part of the Mechanical Engineering Commons

How does access to this work benefit you? Let us know!

\section{Publisher's Statement}

NOTICE: this is the author's version of a work that was accepted for publication in Materials

Science and Engineering A. Changes resulting from the publishing process, such as peer review, editing, corrections, structural formatting, and other quality control mechanisms may not be reflected in this document. Changes may have been made to this work since it was submitted for publication. A definitive version was subsequently published in Materials Science and Engineering A, 392, 1-2, (02-15-2005); 10.1016/j.msea.2004.09.062

\section{Original Citation}

Shi, J., Darzens, S., and Karlsson, A. M., 2005, "Aspects of the Morphological Evolution in Thermal Barrier Coatings and the Intrinsic Thermal Mismatch Therein," Materials Science and Engineering: A, 392(1-2) pp. 301-312.

This Article is brought to you for free and open access by the Mechanical Engineering Department at EngagedScholarship@CSU. It has been accepted for inclusion in Mechanical Engineering Faculty Publications by an authorized administrator of EngagedScholarship@CSU. For more information, please contact library.es@csuohio.edu. 


\title{
Aspects of the morphological evolution in thermal barrier coatings and the intrinsic thermal mismatch therein
}

\author{
J. Shi, S. Darzens, A.M. Karlsson* \\ Department of Mechanical Engineering, University of Delaware, Newark, DE 1976, USA
}

\section{Introduction}

Thermal barrier coatings (TBCs) are multilayered systems used in the hot section of gas turbines to protect the superalloy from degradation during thermal exposure. By applying coatings on critical components, the gas temperature can be increased in the turbine, thus decreasing the fuel consumption. Moreover, the coating can extend the life of gas turbine components, hence lowering the life cycle cost. However, this potential is currently challenged by premature TBC-failures that are not completely understood.

The lack of understanding of TBC-failures can primarily be linked to the complex structure of a TBC in combination with evolving microstructure. A TBC consists of two primary layers that are deposited on the superalloy: a metallic bond-coat for oxidation protection and a ceramic

\footnotetext{
* Corresponding author. Tel.: +1 302831 6437; fax: +1 3028313619 .

E-mail address: karlsson@me.udel.edu (A.M. Karlsson).
}

top-coat for thermal protection, Fig. 1. Active cooling of the superalloy sustains a thermal gradient over the top-coat. The bond-coat protects the superalloy from oxidizing by providing aluminum to form an alpha-aluminum $\left(\alpha-\mathrm{Al}_{2} \mathrm{O}_{3}\right)$ scale between the bond-coat and top-coat, thus sacrificing itself. The oxide scale is frequently referred to as the thermally grown oxide (TGO). As the TGO is formed, the bond-coat is depleted of aluminum, resulting in evolution of microstructure and thermo-mechanical properties of the bond-coat.

Most failures are associated with a separation of the ceramic top-coat from the multilayered structure. There are a range of failures that occur, for example various forms of thermal fatigue [1], foreign object damage [2], and thermal shock [3]. This study will focus on one particular case of thermal fatigue. Of particular interest will be the failure mode associated with morphological instabilities [4]. The observation of this failure mode is limited to platinum-modified aluminidebond-coat Pt-(AINi). The current understanding of the development of morphological instabilities is based on exper- 

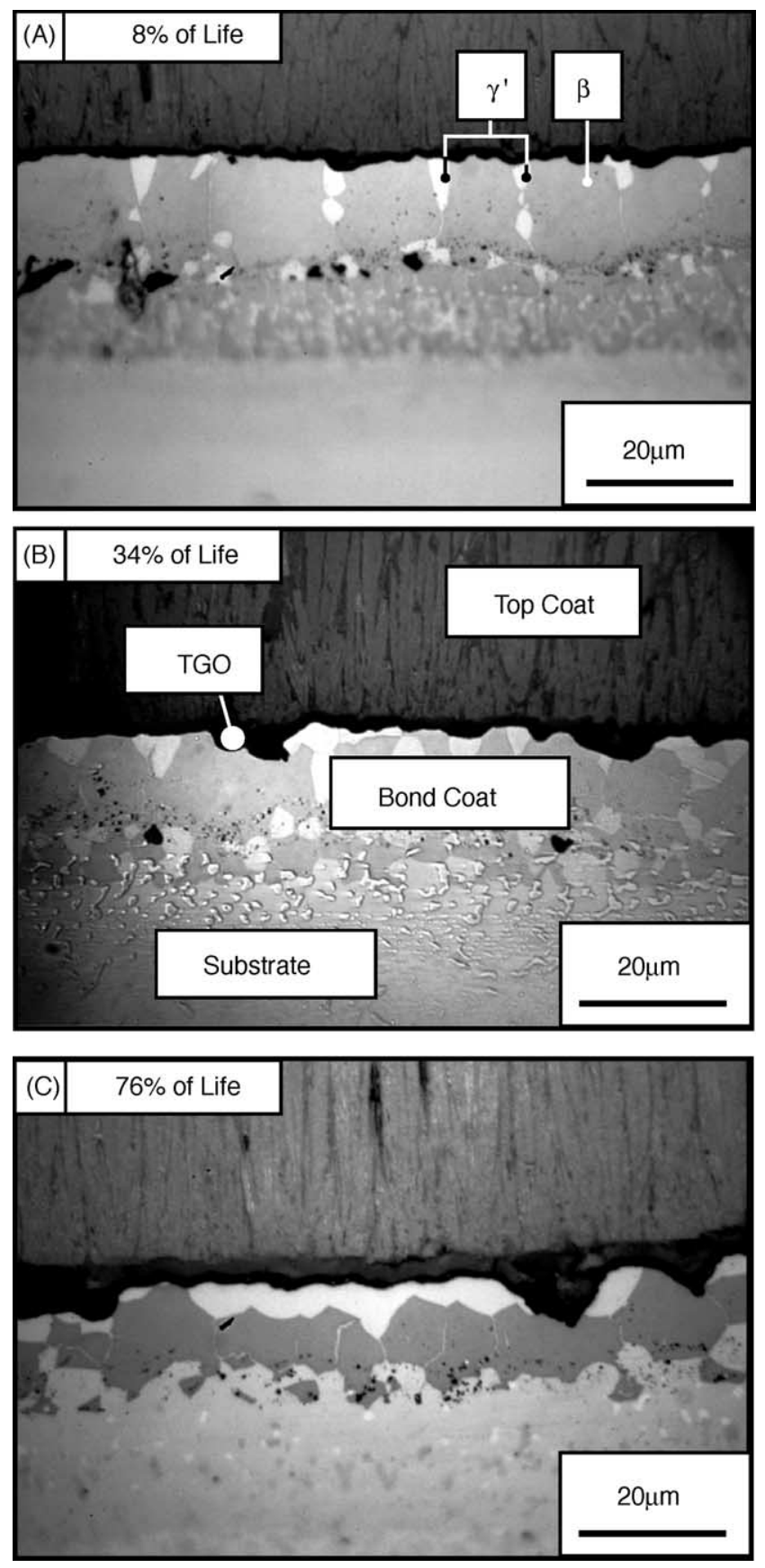

Fig. 1. Optical images of etched cross-sections of furnace cycle tested specimens at different fractions of life, showing the location of the $\beta / \gamma^{\prime}$-phases relative to the TGO instability. (A) $8 \%$ of life; (B) $34 \%$ of life; and (C) $76 \%$ of life.

imental, numerical, and analytical [1,4-10]. Several factors combined cause the morphological instabilities. These are:

(i) the intrinsic thermal mismatch between bond-coat and $\mathrm{TGO}$, causing large compressive stresses in the TGO at ambient temperature;

(ii) the initial imperfection in the bond-coat/interface surface, serving as nucleation sites for the instabilities [4]; (iii) the lengthening growth strain in the TGO, causing increasing compressive stress during thermal exposure $[1,5,11]{ }^{1}$

(iv) the crack-like imperfection in the top-coat, allowing the TGO to move away from the top-coat $[8,13]$;

(v) the yielding and high temperature creep in the bondcoat, accommodating the TGO-deformation $[1,6]$;

(vi) the high-temperature TGO creep, allowing the TGO to relax at higher temperatures [6], and thermal cycling, "resetting" the stresses for each cycle [5].

Morphological instabilities will not occur if one of these six conditions is absent. It is the balance between the growth strain, the thermal cycling and the inelastic response of bondcoat and TGO that governs the behavior. These interactions were described in [1], to which the reader is referred to for a complete discussion.

A common challenge to the six conditions listed above is that these are valid for most TBC-systems, including those that do not exhibit morphological instabilities. We will show that the morphological instabilities are due to the relatively low bond-coat yield and creep strength at high temperature. Low threshold values for inelastic response at high temperature are characteristic for Pt-modified aluminide. We will also see that properties such as thermal mismatch between bond-coat and substrate and the martensitic transformation can enhance the rate of growth.

\section{Some characteristics of Pt-modified aluminide bond-coats}

Pt-modified aluminide bond-coats form a relatively pure and slow growing $\alpha-\mathrm{Al}_{2} \mathrm{O}_{3}$, thus are more resistant to failure. In its initial state, the bond-coat consists primarily of $\beta$-phase (NiAl). Recently, some critical mechanical properties measurements have been published, e.g., [14-17]. These show that the bond-coat yield strength is temperature-dependent and that the yield strength at operating temperatures is remarkably low, Fig. 2A [14]. Furthermore, two dominant transformations are observed in Pt-modified diffusion aluminide: martensitic phase transformation (which occurs on a cyclic basis) and the growth of $\gamma^{\prime}$-grains on the expense of $\beta$-grains (which is monotonic, non-reversible).

The martensitic transformation is a cyclic and reversible transformation. It is a diffusionless shearlike phasetransformation associated with relatively large volume changes, which can introduce large strain in a system [9], Fig. 2B. The martensitic transformation in Al-rich NiAl alloys was documented already in 1968 by Rosen and Goebel [18], but has not until recently received attention

\footnotetext{
${ }^{1}$ combination of high temperature TGO and bond-coat creep, together with the TGO growth strain, results in a "growth stress" in the TGO. This stress is typically determined by measuring the room temperature TGOstress and subtracting the stress caused by thermal mismatch [12].
} 


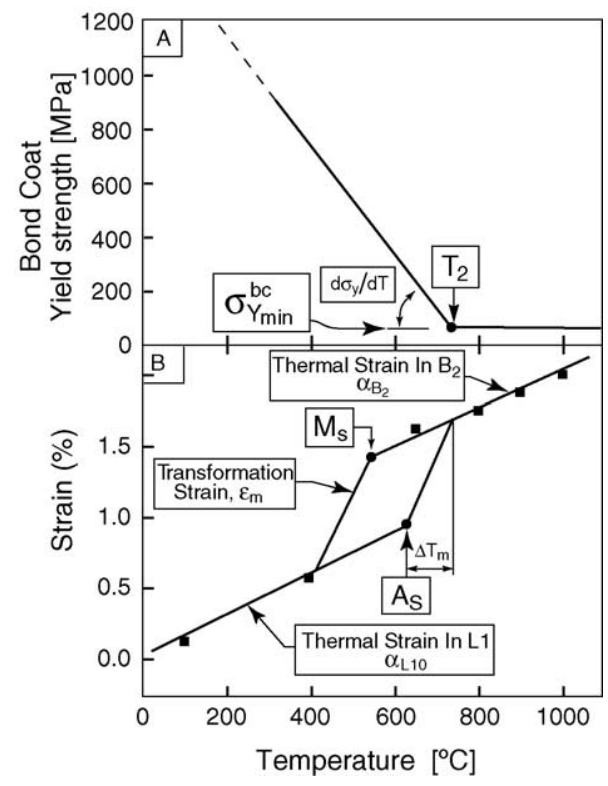

Fig. 2. (A) Yield strength and (B) thermal strain of the bond-coat materials [15].

with respect to Pt-modified aluminide bond-coats [14-16]. The martensitic transformation is thermally-induced, rather than stress-induced. The effect of cyclic martensitic phase transformation on the morphological instabilities was addressed in [9]. In particular it was seen that the martensitic phase transformation cannot by itself drive the instabilities, but that the rate of instability growth becomes sensitive to the thermal mismatch with the substrate. However, no insight in the cause of the sensitivity was offered. This will be addressed in the current paper.

The transformation of $\beta$ - to $\gamma^{\prime}$-phase in Pt-aluminide near the TGO/bond-coat interface (Fig. 1) is mainly due to the depletion of aluminum as the $\mathrm{Al}$ diffuses out to form the TGO at the bond-coat surface [19], but also due to the Ni diffusion from the substrate to the bond-coat. The thermomechanical properties - such as thermal expansion and yield strength-are quite different for the two phases [20]. A preliminary numerical study of the influence the formation of $\gamma^{\prime}$-phase on the morphological instability was conducted [10]. However, that study was limited in its scope and did not discuss the effect of the mismatch between bond-coat and substrate. We will extend this discussion in the current paper.

\section{Model}

We adopt the finite element model developed previously $[5,10]$, Fig. 3, utilizing the commercially available program ABAQUS [21]. For the current simulation we are using fournode generalized plane strain elements. The thermal expansion coefficient for bond-coat, substrate, TGO, and top-coat are denoted $\alpha_{\mathrm{bc}}, \alpha_{\mathrm{sub}}, \alpha_{\mathrm{TGO}}$, and $\alpha_{\mathrm{tc}}$, respectively.

Growth in the TGO is simulated by imposing stress-free strains in accordance with the user subroutine uexpan [21].

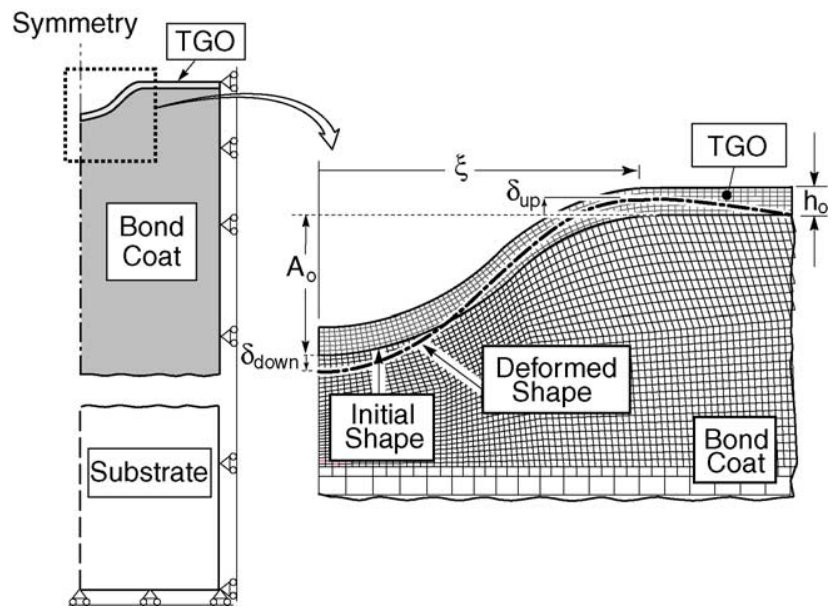

Fig. 3. The finite element model. The TGO is initially $0.5 \mu \mathrm{m}$, the bond-coat is $50 \mu \mathrm{m}$, and the substrate is $2 \mathrm{~mm}$. The top-coat is assumed to be $150 \mu \mathrm{m}$ for the cases when it is modeled (not shown).

The in-plane strain is imposed uniformly through the TGOthickness, while the thickening component is applied at the elements closest to the bond-coat. This is consistent with experimental observations [4]. In a similar manner the martensitic phase transformation is imposed as a stress-free strain, assuming that the transformation is thermally-induced, independent of stress. The heat dissipation associated with martensitic transformation is ignored.

For the case when the grain structure is studied, e.g., the $\gamma^{\prime}$ - and $\beta$-phases, the model is adopted from [10] and extended for the current set of simulations, as shown in Fig. 4.

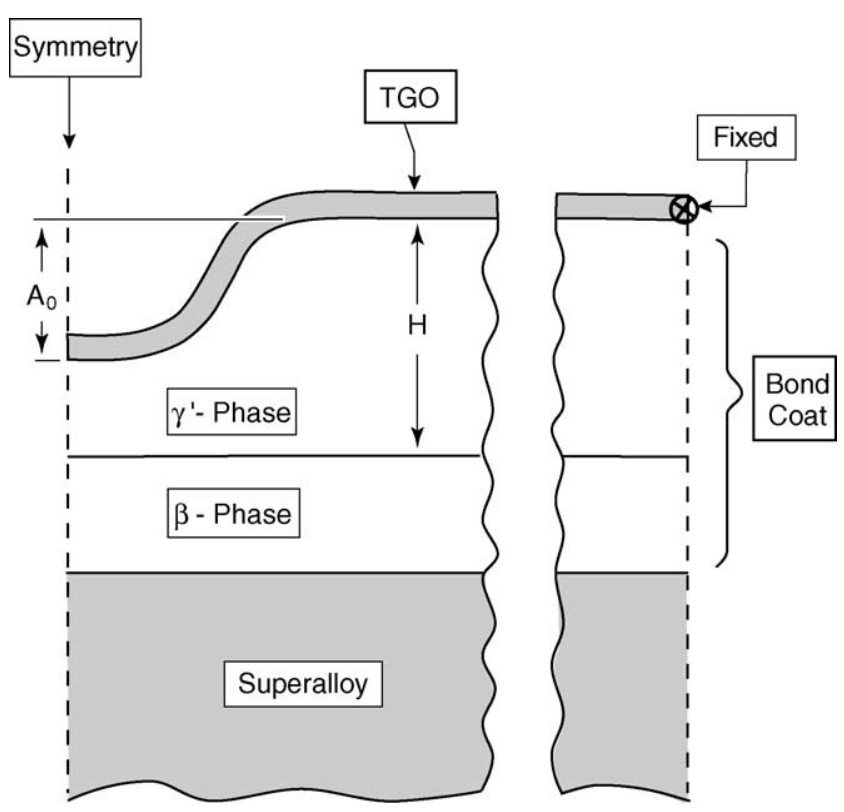

Fig. 4. The generalized plane strain model showing the location of the $\beta / \gamma^{\prime}-$ phases. $H$ is the thickness of the $\gamma^{\prime}$-phase; $A_{0}$ is the depth of the initial imperfection. 
To keep the simulations tractable, allowing only for the critical parameters to be investigated, we do not simulate the anisotropy of the various grains, nor do we consider crystal plasticity. Even though these simplifications may influence the local behavior, we believe that the overall behavior is not affected. Moreover, these simplifications can easily be eliminated in a future study, where the interaction of the anisotropy can be incorporated.

\section{Simulations: results and discussion}

\subsection{Thermal mismatch between bond-coat and substrate}

In this section, we will discuss how the thermal mismatch influences the development of stresses and strain in the TBC. We will consider two scenarios, excluding and including the ceramic top-coat. The latter corresponds to an intact system,

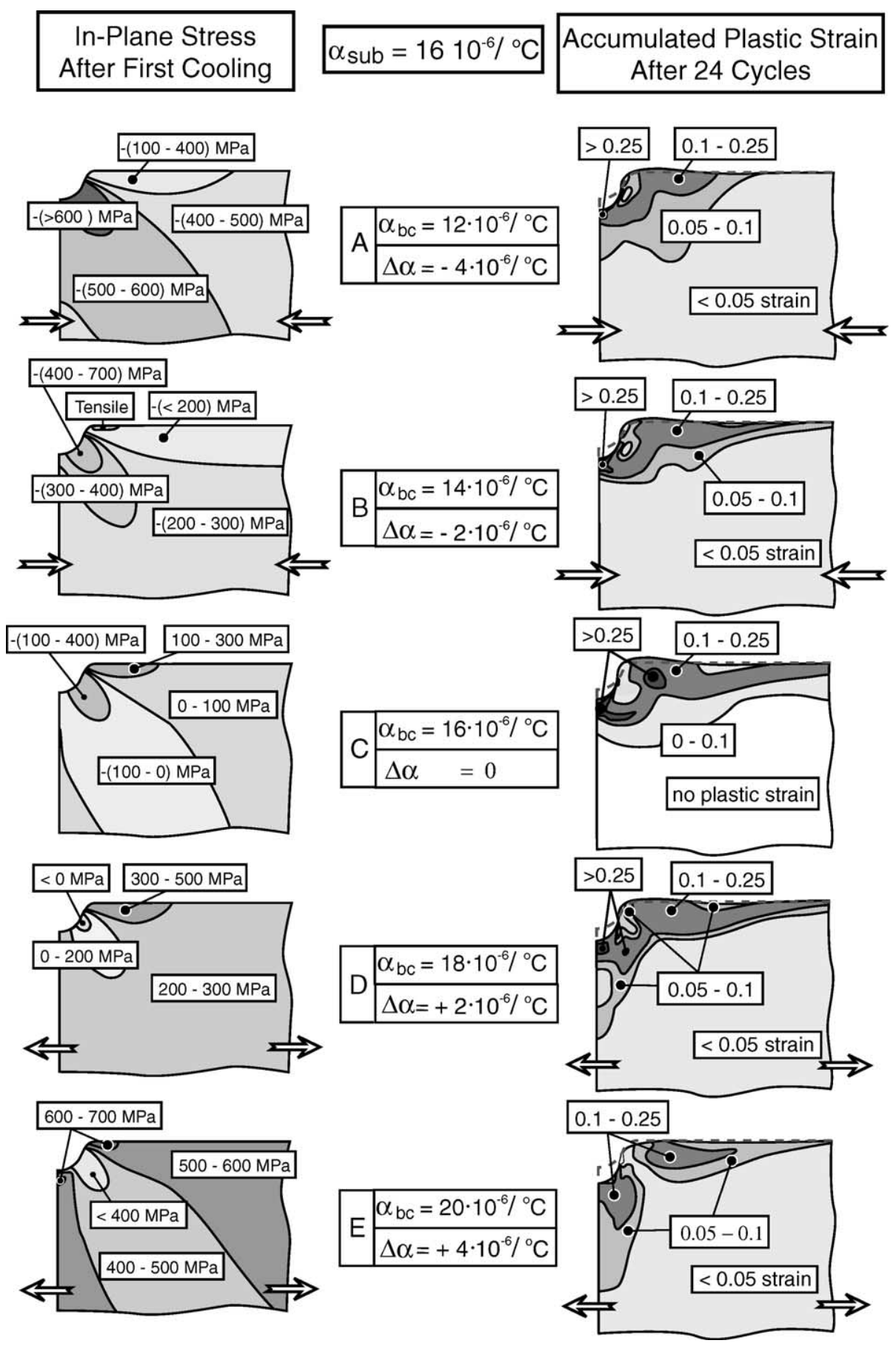

Fig. 5. In-plane stresses after first cooling and accumulated plastic strain after 24 cycles in the bond-coat for $\alpha_{\mathrm{sub}}=16 \times 10^{6}{ }^{\circ} \mathrm{C}^{-1} ;(\mathrm{A}) \alpha_{\mathrm{bc}}=12 \times 10^{6}{ }^{\circ} \mathrm{C}^{-1}$; (B) $\alpha_{\mathrm{bc}}=14 \times 10^{6}{ }^{\circ} \mathrm{C}^{-1}$; (C) $\alpha_{\mathrm{bc}}=16 \times 10^{6}{ }^{\circ} \mathrm{C}^{-1}$; (D) $\alpha_{\mathrm{bc}}=18 \times 10^{6}{ }^{\circ} \mathrm{C}^{-1}$; and (E) $\alpha_{\mathrm{bc}}=20 \times 10^{6}{ }^{\circ} \mathrm{C}^{-1} .\left(\sigma_{Y}^{\mathrm{bc}}\right)_{\mathrm{HT}}=20 \mathrm{MPa}$, and $\alpha_{\mathrm{TGO}}=8.5 \times 10^{6}{ }^{\circ} \mathrm{C}^{-1}$. The arrows indicate the sign of the overall mismatch stress between bond-coat and substrate. $\Delta \alpha \equiv \alpha_{\mathrm{bc}}-\alpha_{\mathrm{sub}}$. 


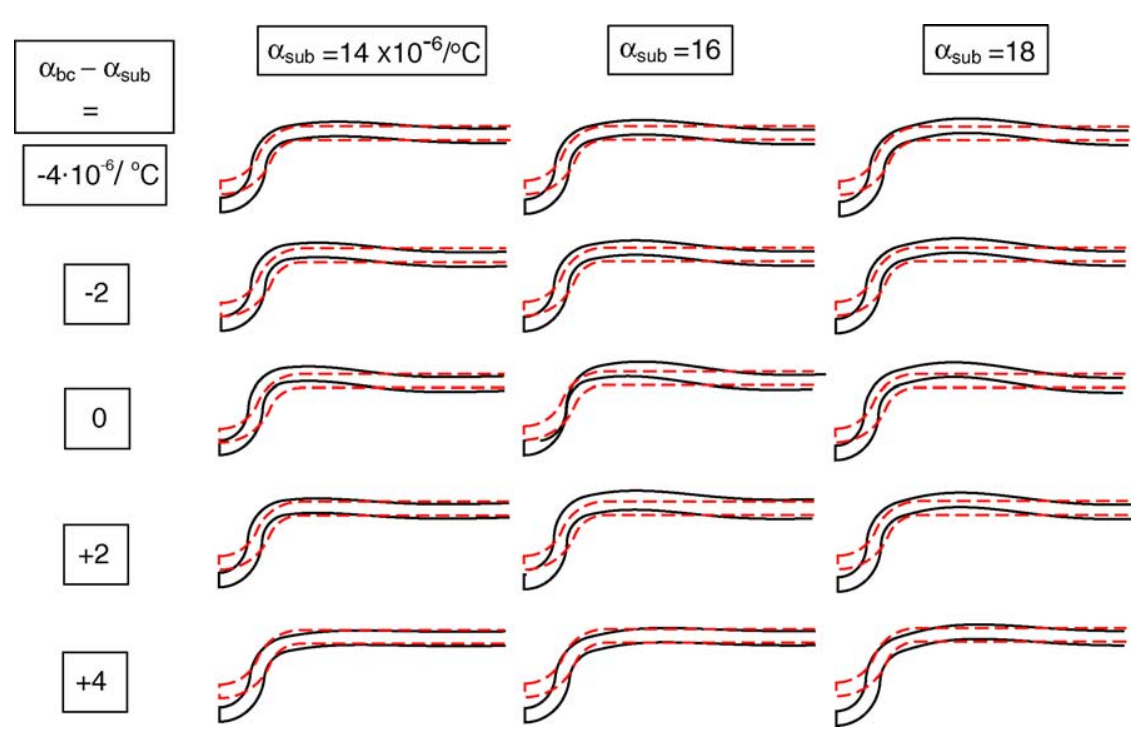

Fig. 6. Deformation of the TGO interface after 24 cycles for various thermal mismatches between bond-coat and substrate. Negative mismatch results in overall compressive bond-coat stresses.

while the former corresponds to a case where the top-coat either has spalled, or a significant interfacial crack has developed, eliminating the constraint from the top-coat.

\subsubsection{Absent top-coat}

When the top-coat is absent, we will monitor the system evolution through the development of morphological instabilities. In particular, the morphological instabilities are characterized by the amplitude change of an initial imperfection in the bond-coat. We will monitor the amplitude change with three variables (Fig. 2): the downwards displacement in the center of the undulation, $\delta_{\text {down }}$, and the upwards displacement at the periphery of the undulation expressed in magnitude, $\delta_{\text {up }}$, and location, $\xi$. It was suggested in $[8,22]$ that the magnitude of $\delta_{\text {up }}$ and $\xi$ may influence the rate of crack growth in the top-coat, but we will see in the following that these are not good measurements to predict crack growth in the top-coat.

The TBC-system is initially assumed stress-free at its highest temperature. ${ }^{2}$ When the system is cooled, two main sources contribute to the stresses in the bond-coat: (i) thermal mismatch between bond-coat and TGO, and (ii) thermal mismatch between bond-coat and substrate. The former case results in a local stress field adjacent to the TGO, which varies in sign and magnitude depending on the geometry of the imperfection. In the latter case, the bond-coat stresses are tensile if the thermal expansion of the bond-coat, $\alpha_{\mathrm{bc}}$, is larger than that of the substrate, $\alpha_{\text {sub }}$, i.e., $\alpha_{\mathrm{bc}}-\alpha_{\text {sub }}>0$, and compressive if $\alpha_{\mathrm{bc}}-\alpha_{\mathrm{sub}}<0$.

When the bond-coat and the substrate have the same thermal expansion (Fig. 5C), stresses develop only around the imperfection and adjacent to the TGO. Thus, the plastic strain is

\footnotetext{
${ }^{2}$ For simplicity, we assume that the deposition temperature is approximately the same as the operating temperature.
}

confined to this area and most of the bond-coat remains elastic throughout the cycle. When there is a thermal mismatch between the bond-coat and substrate, the bond-coat undergoes overall yielding for yield strength typical of a $\beta$-grain. The bond-coat will yield in tension if the thermal expansion of the bond-coat is larger than that of the substrate, $\alpha_{\mathrm{bc}}-\alpha_{\mathrm{sub}}>0$ (Fig. 5D and E), and in compression if $\alpha_{\mathrm{bc}}-\alpha_{\mathrm{sub}}<0$ (Fig. 5A and $\mathrm{B}$ ). The shape of the TGO after 24 cycles relates to the sign of the mismatch, in Fig. 6. The imperfection and-for large enough thermal mismatch - its periphery move into the bond-coat for the case of tensile mismatch. For the cases of no mismatch and compressive mismatch, upward motion of the periphery and downward motion at the center of the imperfection are observed.

However, it is not only the sign of the mismatch that governs the behavior: the absolute values directly influence the shape change. This is quantified by $\delta_{\text {down }}, \delta_{\text {up }}$, and $\xi$, where the results are summarized in Fig. 7. For the range of parameters studied, the location of the peak moves to the right in Fig. 6 (increasing values in Fig. 7D). The upwards deformation increases with increasing thermal expansion of the substrate, where it increases most rapidly for $\alpha_{\mathrm{bc}}-\alpha_{\mathrm{sub}}>0$. The deformation in the center of the undulation depends on the absolute value of the mismatch, increasing with increasing thermal expansion of bond-coat and substrate.

The total amplitude change, $\delta_{\text {tot }}=\delta_{\text {up }}+\delta_{\text {down }}$, is independent of the thermal expansion of the bond-coat but increases with increasing thermal expansion of the substrate, Fig. 7A. This can be explained by the following: the mismatch between the bond-coat and substrate causes an overall yielding of the bond-coat during cooling. Concurrently, high compressive stresses develop in the TGO, Fig. 8. When the bond-coat is in overall yield, the TGO can relax its strain energy by pushing on the soft bond-coat, thus causing permanent deformation of the TGO-bond-coat interface. All together, when 


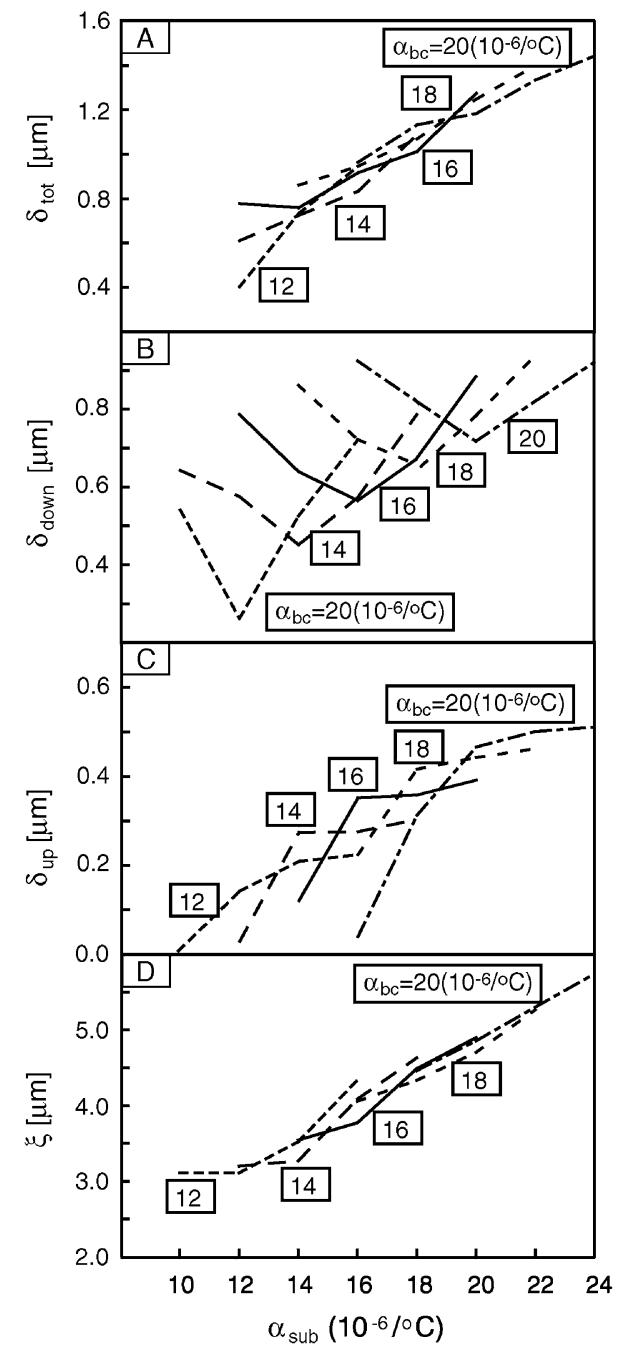

Fig. 7. Deformation of the bond-coat/TGO interface as a function of thermal expansion of the substrate, after 24 cycles for a range of thermal expansions of the bond-coat: (A) total amplitude change, $\delta_{\text {tot }}$; (B) downwards deformation at the center of the imperfection, $\delta_{\text {down }} ;(C)$ upwards motion at the periphery of the imperfection, $\delta_{\text {up }}$; and (D) location of maximum deflection, $\xi \cdot\left(\sigma_{Y}^{\mathrm{bc}}\right)_{\mathrm{HT}}=20 \mathrm{MPa}$, and $\alpha_{\mathrm{TGO}}=8.5 \times 10^{6}{ }^{\circ} \mathrm{C}^{-1}$.

the bond-coat is in overall yielding, the mismatch between the substrate and the TGO governs the behavior.

The TGO stresses are sensitive to the thermal expansion coefficients of the bond-coat, Fig. 8. In general, the TGO stresses are compressive, caused by the growth strain and by the thermal mismatch. However, the system strives to release the strain energy due to the compressive stress by distorting the TGO. This results in a stress gradient that can involve both compressive and tensile stresses. The tensile stresses can become large enough to cause cracking of the TGO. The location of the tensile stresses will depend on the shape of the TGO [7] and the yield strength of bond-coat, Fig. 8. Fig. 9 illustrates how the strain energy in the TGO changes for various parameters. For example, if the bond-coat high-temperature yield strength is increased, a significantly smaller shape change is obtained (see discussion below, Fig. 12) due to the limited region of plastic deformation. Thus, less energy will be dissipated in yielding and the TGO will store more strain energy. The strain energy increases with increasing bond-coat thermal expansion coefficient, since increasing $\alpha_{\mathrm{bc}}$ results in an increasing mismatch strain between bond-coat and TGO.

Additionally, the numerical investigations show the following. A decrease in the thermal expansion of the TGO-which corresponds to an increase in system mismatch - results in an increase in the amplitude change (Fig. 10), so does a decrease in TGO growth stress (Fig. 11). ${ }^{3}$ Similarly, the amplitude change decreases when the hightemperature bond-coat yield strength $\left(\sigma_{Y}^{\mathrm{bc}}\right)_{\mathrm{HT}}$ is increased (Fig. 12). For large enough high-temperature bond-coat yield strengths, overall yielding does not occur. The bond-coat only yields at the vicinity of the TGO. For these cases, the total amplitude change is independent of $\alpha_{\text {sub }}$.

\subsubsection{Including top-coat}

The scenario described in the previous sub-section alters when the top-coat is included in the model (corresponding to an intact system, rather than a spalled system). In this case, the bond-coat deformation is suppressed due to the constraint from the top-coat. Even though the top-coat has a low elastic modulus compared to the other constituents (20 GPa and $110 \mathrm{GPa}$, for top-coat and bond-coat, respectively) it is stiff relative to the bond-coat due to its thickness and that it is linear-elastic throughout the loading cycle. The morphology change is therefore suppressed and becomes vanishing small. Hence, we will monitor the top-coat stress around the imperfection rather than the morphology change. For simplicity, the constitutive law for the ceramic top-coat is assumed to be independent of the state of stress. This is not a completely accurate description of the top-coat which due to its porous structure exhibits a more complex stress strain behavior which is explored by [23]. However, to keep the current set of calculations to a tractable scheme, we will use the linearelastic relationship. The full description developed in [23] can be adopted for future studies.

The top-coat stresses are primarily ruled by the mismatch between the top-coat and the substrate, and secondary determined by the thermal expansion of the bond-coat (Figs. 13-17). After 24 cycles, the in-plane stress, $\sigma_{11}$, is overall compressive at ambient (Fig. 13A). At maximum temperature a region of tensile stress is present, which could result in lateral cracks in the top-coat (even though the stresses are moderate, the top-coat can only tolerate moderate tensile stresses due to its porous structure). The in-plane stresses at elevated temperature are indifferent with respect to thermal mismatch (Fig. 14). The stresses at this temperature are a reflection of the growth strain in the TGO, and increases on a cyclic base (not shown).

\footnotetext{
${ }^{3}$ The growth stress of the TGO is modeled by imposing a hightemperature yield strength. The justification of this simplification was discussed in [7].
} 

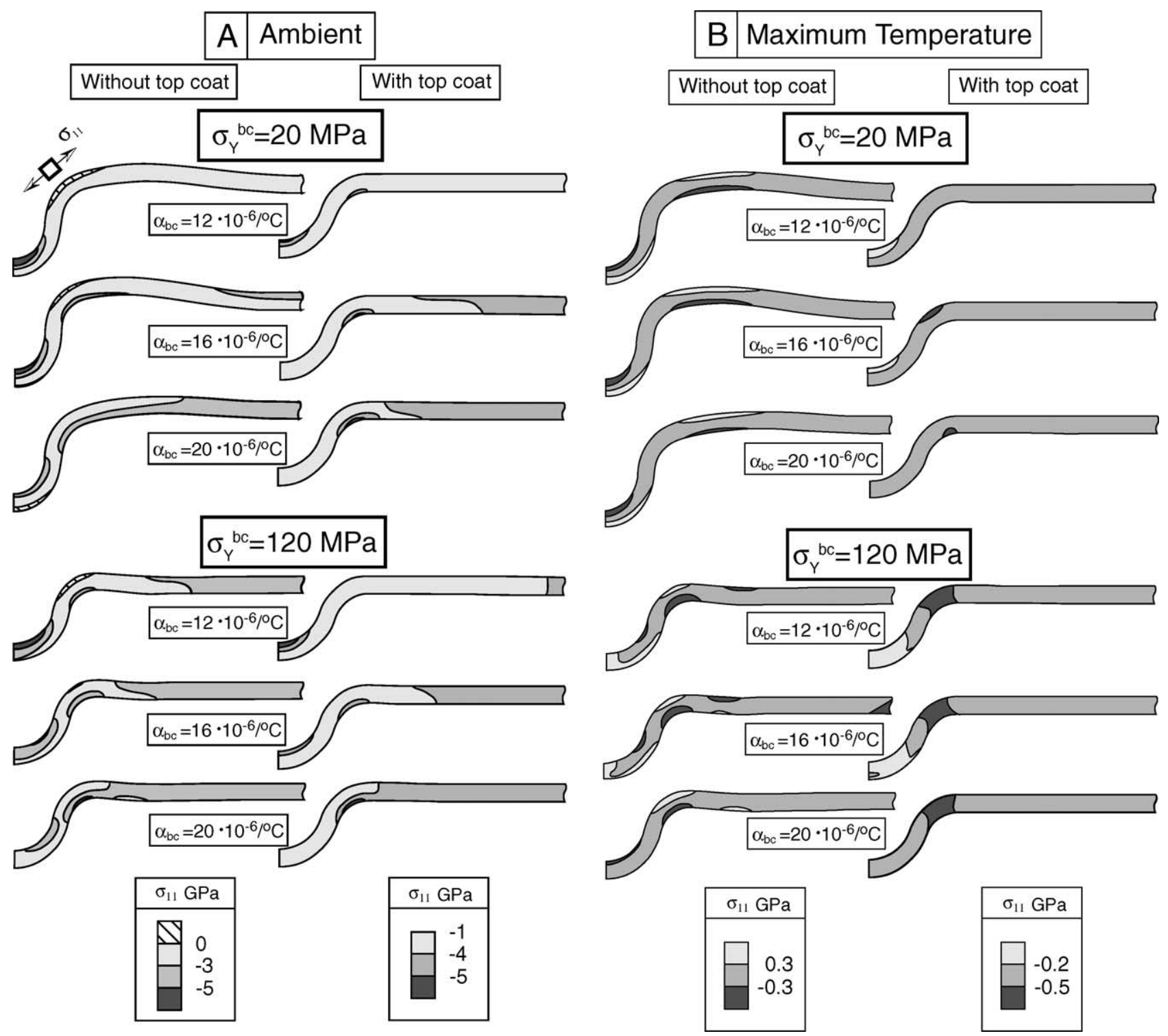

Fig. 8. Stresses in the TGO tangential to the TGO-bond-coat interface, without top-coat (left column) and with top-coat (right column), after 24 cycles, at (A) ambient and (B) elevated temperatures for high-temperature bond-coat yield strength of $\left(\sigma_{Y}^{\text {bc }}\right)_{\mathrm{HT}}=20 \mathrm{MPa}$ and $\left(\sigma_{Y}^{\mathrm{bc}}\right)_{\mathrm{HT}}=120 \mathrm{MPa}$.

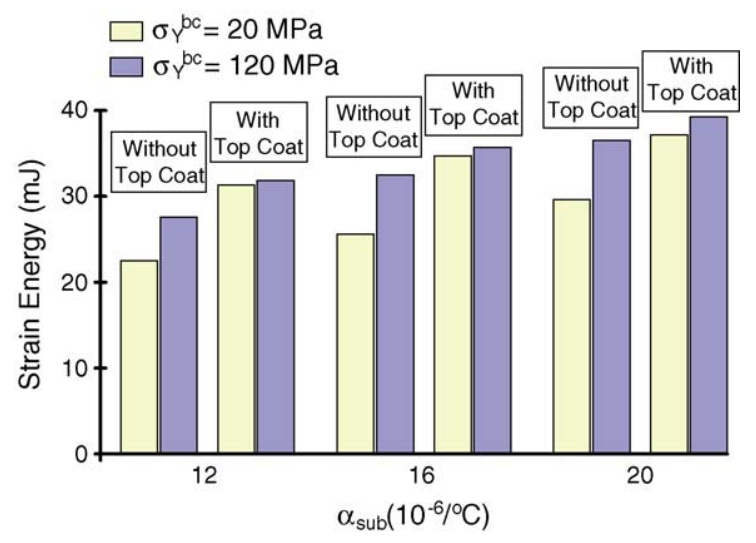

Fig. 9. Strain energy in TGO for some characteristic cases.

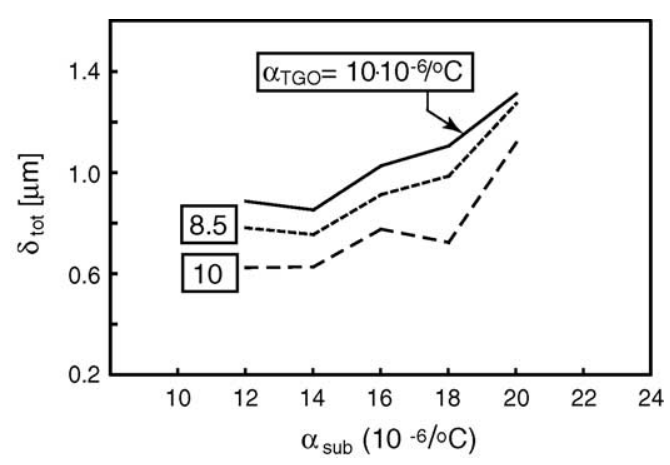

Fig. 10. Total amplitude change $\delta_{\text {tot }}$ of the bond-coat/TGO interface as a function of thermal expansion of the substrate, after 24 cycles, for various thermal expansions of the TGO, $\left(\sigma_{Y}^{\mathrm{bc}}\right)_{\mathrm{HT}}=20 \mathrm{MPa}, \alpha_{\mathrm{bc}}=16 \times 10^{6}{ }^{\circ} \mathrm{C}^{-1}$, and $\alpha_{\text {sub }}=16 \times 10^{6}{ }^{\circ} \mathrm{C}^{-1}$. 


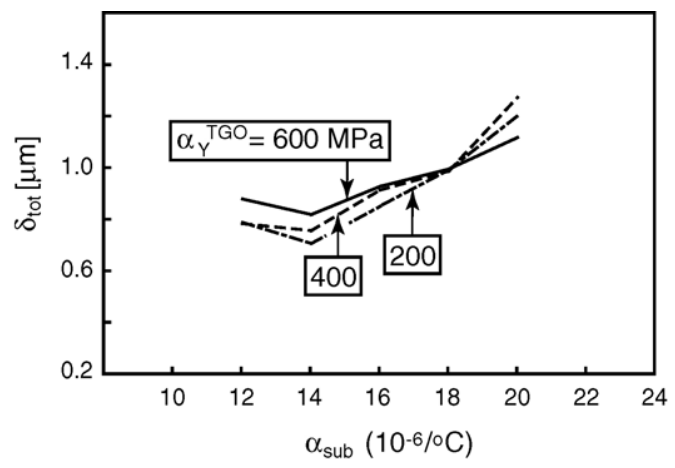

Fig. 11. Total amplitude change of the bond-coat/TGO interface as a function of thermal expansion of the substrate, after 24 cycles, for various growth stresses of the TGO, $\left(\sigma_{Y}^{\mathrm{bc}}\right)_{\mathrm{HT}}=20 \mathrm{MPa}, \alpha_{\mathrm{bc}}=16 \times 10^{6}{ }^{\circ} \mathrm{C}^{-1}$, and $\alpha_{\text {sub }}=16 \times 10^{6}{ }^{\circ} \mathrm{C}^{-1}$.

The out-of-plane stresses, $\sigma_{22}$, correspond to the "crackopening" stresses for the cracks parallel to the TGO. Since these cracks are directly associated with the final spallation of the top-coat, the out-of-plate stresses are critical to the system performance. These are also the stresses that are considered suppressing the morphological instabilities. The out-of-plane stress is characterized by a tensile stress in the center of the imperfection and a compressive stress at the periphery of the imperfection (Fig. 15). The region of maximum tensile stress is located in the vicinity of the inflection point of the imperfection. A propagating crack will be slowed down when it reaches this compressive region at the periphery, growing in pure mode II [22]. The crack-opening stress increases in magnitude (both tensile and compressive stresses becomes larger) when the yield strength of the bond-coat is increased, (Fig. 15C).

For the range of properties considered, the crack opening top-coat stress show only a limited dependence of the thermal expansion of the substrate and of the bond-coat (Fig. 16). The stresses depend mostly on the bond-coat yield strength (Fig. 15C) and the growth stress (not shown). The location

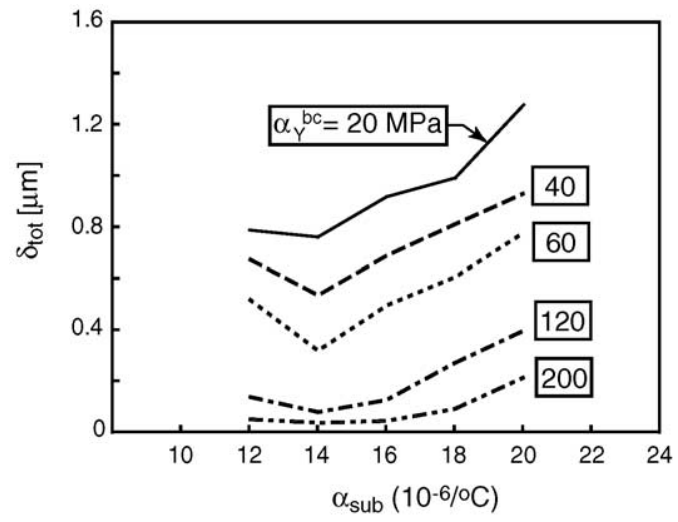

Fig. 12. Total amplitude change of the bond-coat/TGO interface as a function of thermal expansion of the substrate, after 24 cycles, various high temperature yield stresses in the bond-coat: $\alpha_{\mathrm{bc}}=16 \times 10^{6}{ }^{\circ} \mathrm{C}^{-1}$, $\alpha_{\text {sub }}=16 \times 10^{6}{ }^{\circ} \mathrm{C}^{-1}$, and $\alpha_{\mathrm{TGO}}=8.5 \times 10^{6}{ }^{\circ} \mathrm{C}^{-1}$.

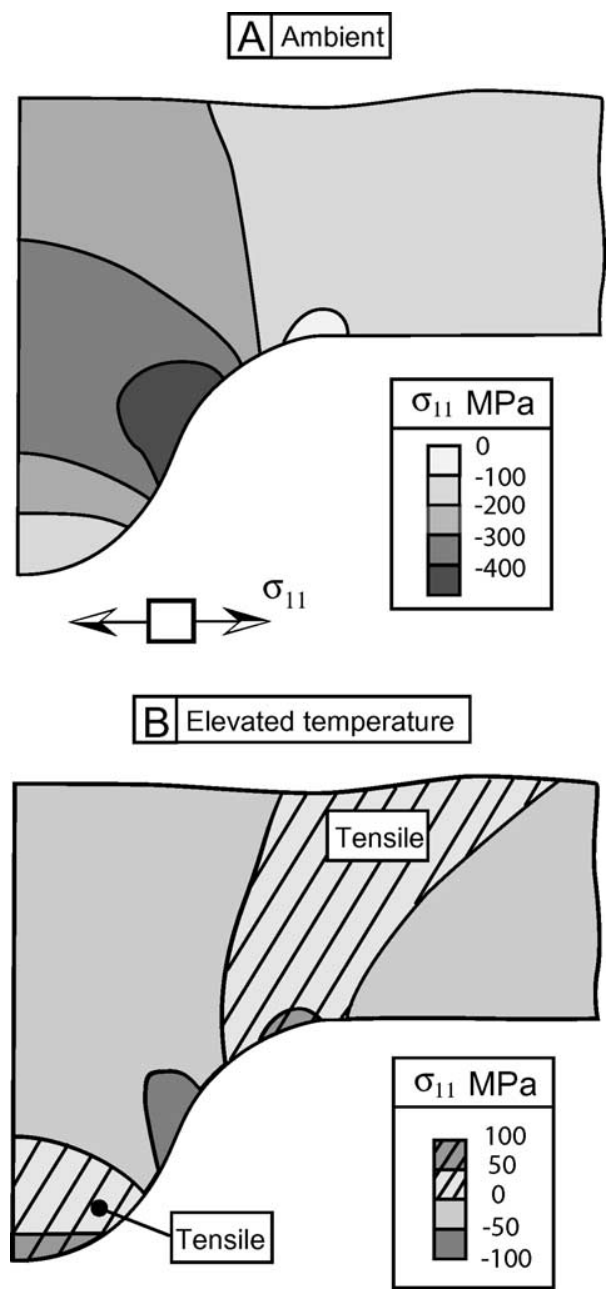

Fig. 13. In-plane stresses in the top-coat after 24 cycles at (A) ambient and (B) elevated temperature.

of the maximum stress changes and the difference between ambient and room temperature stresses becomes smaller with thermal cycling (Fig. 17) since the major contribution to $\sigma_{22}$ is due to the accumulation of inelastic strain in the bond-coat and the TGO, in combination of the curved surface. This evolution may contribute to driving or arresting a crack. The growth of the crack will be investigated in a later study. Preliminary work of crack growth may be found in $[22,24]$.

That the stresses are independent of the sign of the bondcoat-substrate mismatch may seem counterintuitive from what was observed absent top-coat (e.g., Figs. 5 and 6). However, with the constraint from the top-coat and the relative softness of the bond-coat (due to yielding), the bond-coat will accommodate the thermal mismatch stresses during the heating-cooling sequence. The reverse yielding upon reheating is of the same magnitude as that of the forward yielding. Consequently, no resultant shape change occurs. Instead of accumulating the added system energy created by the TGO growth and thermal mismatch, the energy is transformed to elastic strain manifested as stresses in the top-coat and increased strain energy of the TGO (Fig. 9). 

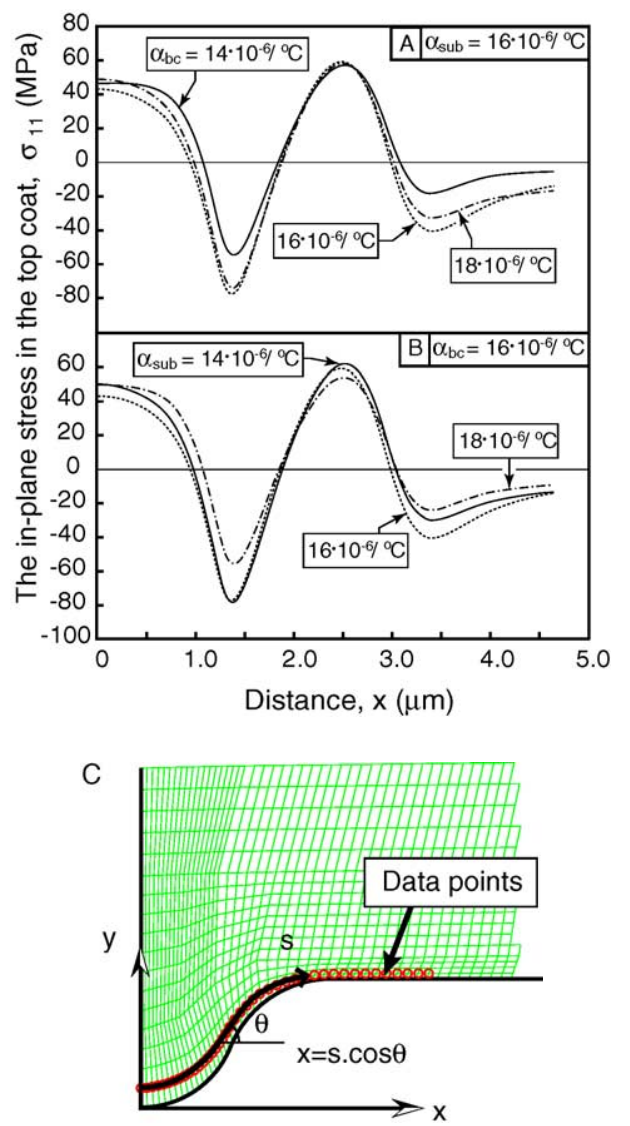

Fig. 14. The in-plane stress in the top-coat at elevated temperature as a function of $x$-coordinate, for various combinations of thermal expansions, after 24 cycles. (A) $\alpha_{\text {sub }}$ constant, (B) $\alpha_{\text {bc }}$ constant, and (C) definition of $x$.

\subsection{Presence of $\gamma^{\prime}$-phase}

The bond-coat microstructure is slowly transformed from being primary $\beta$-grains to include both $\beta$-and $\gamma^{\prime}$-phase $(\mathrm{NiAl}$ and $\mathrm{Ni}_{3} \mathrm{Al}$, respectively), Fig. 1 [19], as the bond-coat is depleted of alumina. Some researchers have argued that the volume change associated with this phase transformation cause the imperfection growth. However, the volume change from $\beta$ - to $\gamma^{\prime}$-phase is relatively small and experimental observation indicate that the imperfection are preferentially located in the $\beta$-phase [19]. Moreover, preliminary numerical investigations indicate that the higher yield strength in the $\gamma^{\prime}$-phase discourage imperfection growth [10]. The results discussed in this section pertain to the presence of the two phases as it relates to the thermal mismatch with the substrate. To simplify the simulations, no thermal expansion mismatch is imposed within the bond-coat, but only a yield strength difference, $\left(\sigma_{\mathrm{Y}}^{\beta}\right)_{\mathrm{HT}}=20 \mathrm{MPa}$ and $\left(\sigma_{\mathrm{Y}}^{\gamma^{\prime}}\right)_{\mathrm{HT}}=120 \mathrm{MPa}$ for the $\beta$ and $\gamma^{\prime}$, respectively.

We will limit the parametric study to the case when $\alpha_{\text {sub }}=16 \times 10^{-6}{ }^{\circ} \mathrm{C}^{-1}$ and $\alpha_{\mathrm{bc}}=14 \times 10^{-6}{ }^{\circ} \mathrm{C}^{-1}$, resulting in compressive residual stresses in the bond-coat. Absent topcoat, we saw in Section 4.1.1 that this results in an upwards motion of the bond-coat (repeated in Fig. 18A for clarity).

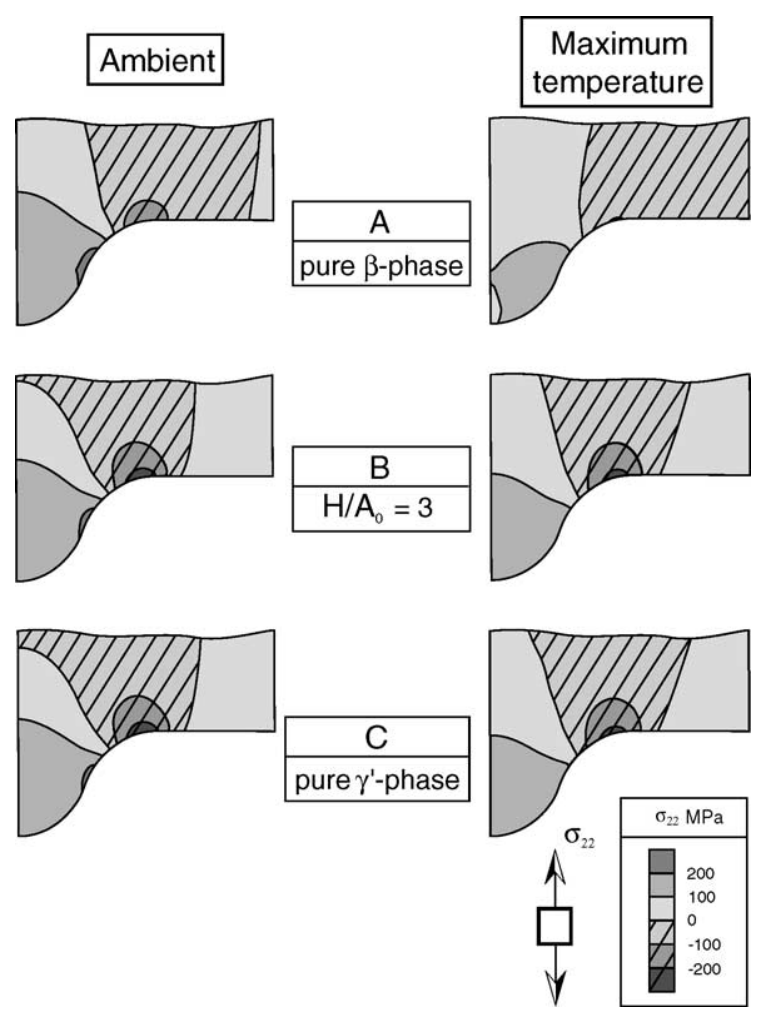

Fig. 15. Out-of-plane stresses at ambient in the top-coat after 24 cycles. (A) for pure $\beta$-phase $\left(\sigma_{Y}^{\mathrm{bc}}\right)_{\mathrm{HT}}=20 \mathrm{MPa}$, (B) for $\gamma^{\prime}$-phase with thickness $H / A_{0}=3$ (Fig. 4), and (C) pure $\gamma^{\prime}$-phase, $\left(\sigma_{Y}^{\mathrm{bc}}\right)_{\mathrm{HT}}=120 \mathrm{MPa}$. $\alpha_{\mathrm{bc}}=16 \times 10^{6}{ }^{\circ} \mathrm{C}^{-1}, \quad \alpha_{\mathrm{bc}}=14 \times 10^{6}{ }^{\circ} \mathrm{C}^{-1}, \quad \alpha_{\mathrm{TGO}}=8.5 \times 10^{6}{ }^{\circ} \mathrm{C}^{-1}$, and $\alpha_{\mathrm{TC}}=11 \times 10^{6}{ }^{\circ} \mathrm{C}^{-1}$.

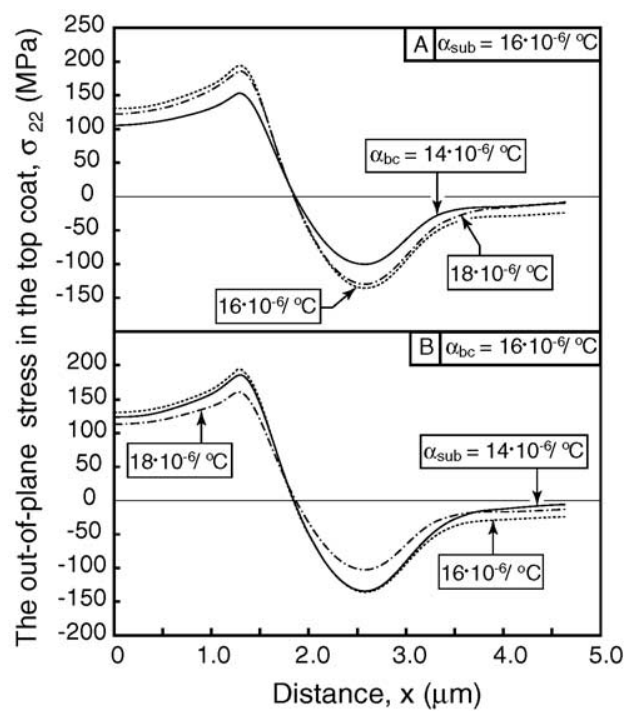

Fig. 16. The out-of-plane stress in the top-coat as a function of $x$ coordinate, for various combinations of thermal expansions, after $24 \mathrm{cy}-$ cles. (see Fig. $14 \mathrm{C}$ for definition of $x$ ): (A) $\alpha_{\text {sub }}=16 \times 10^{6}{ }^{\circ} \mathrm{C}^{-1}$; and (B) $\alpha_{\mathrm{bc}}=16 \times 10^{6}{ }^{\circ} \mathrm{C}^{-1}, \alpha_{\mathrm{TGO}}=8.5 \times 10^{6}{ }^{\circ} \mathrm{C}^{-1}$, and $\alpha_{\mathrm{TC}}=11 \times 10^{6}{ }^{\circ} \mathrm{C}^{-1}$. 


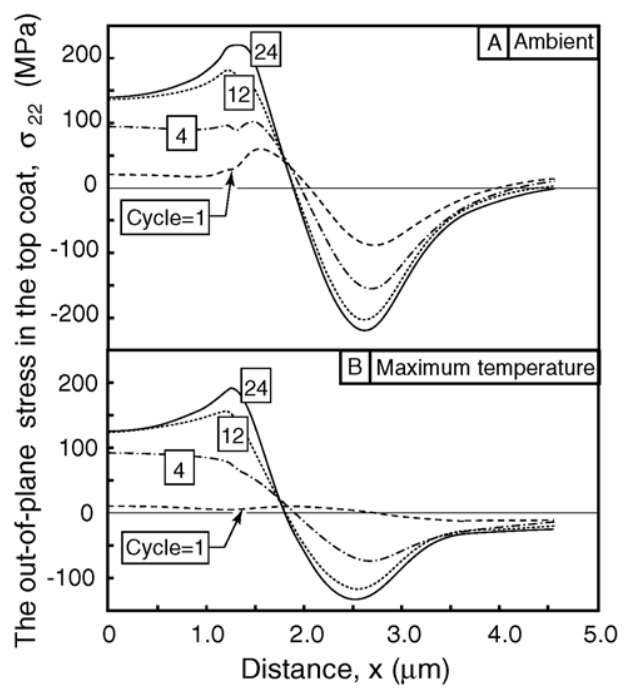

Fig. 17. The evolution of the out-of-plane stresses in the top-coat as a function of $x$-coordinate (see Fig. 14C for definition of $x$ ): (A) ambient; and (B) maximum temperature, $\alpha_{\text {sub }}=16 \times 10^{6}{ }^{\circ} \mathrm{C}^{-1}, \alpha_{\mathrm{bc}}=16 \times 10^{6}{ }^{\circ} \mathrm{C}^{-1}$, $\alpha_{\mathrm{TGO}}=8.5 \times 10^{6}{ }^{\circ} \mathrm{C}^{-1}$, and $\alpha_{\mathrm{TC}}=11 \times 10^{6}{ }^{\circ} \mathrm{C}^{-1}$.

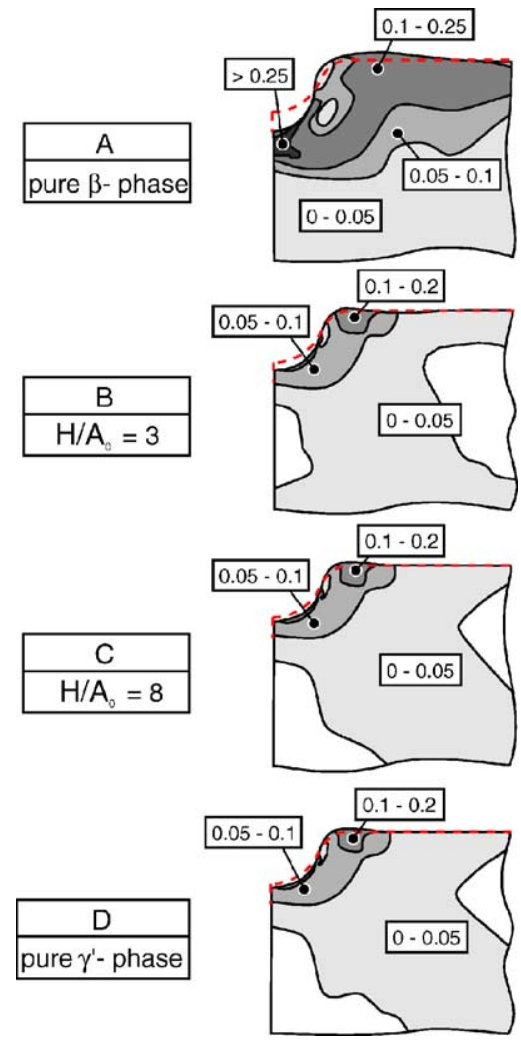

Fig. 18. Accumulated plastic strain after 24 cycles in the bond-coat for various thicknesses of $\gamma^{\prime}$ phase (absent top-coat): (A) for pure $\beta$-phase $\left(\sigma_{Y}^{\mathrm{bc}}\right)_{\mathrm{HT}}=20 \mathrm{MPa}$, (B) for $\gamma^{\prime}$-phase with thickness $H / A_{0}=3$ (Fig. 4), (C) for $\gamma^{\prime}$-phase with thickness $\mathrm{H} / A_{0}=8$, and (D) for pure $\gamma^{\prime}$-phase, $\left(\sigma_{Y}^{\mathrm{bc}}\right)_{\mathrm{HT}}=120 \mathrm{MPa} \quad\left(H / A_{0}=25\right) . \quad \alpha_{\text {sub }}=16 \times 10^{6}{ }^{\circ} \mathrm{C}^{-1}$, $\alpha_{\mathrm{bc}}=16 \times 10^{6}{ }^{\circ} \mathrm{C}^{-1}, \alpha_{\mathrm{TGO}}=8.5 \times 10^{6}{ }^{\circ} \mathrm{C}^{-1}$, and $\alpha_{\mathrm{TC}}=11 \times 10^{6}{ }^{\circ} \mathrm{C}^{-1}$.
If a layer of $\gamma^{\prime}$-phase is present, (Fig. 18B-D), this deformation is suppressed. The $\gamma^{\prime}$-phase has sufficient yield strength to suppress overall yielding, restricting the morphological change. For the range of thicknesses studied, the thickness of the $\gamma^{\prime}$-phase is immaterial.

The results when the top-coat is considered follows directly: compared to the bond-coat with primary $\beta$-grains, Fig. 15A, the $\gamma^{\prime}$-phase results in increase magnitude of the crack opening stresses, Fig. 15B.

\subsection{Martensitic phase transformations}

In this last subsection we will discuss some results pertaining to the martensitic phase transformation that can occur in Pt-modified bond-coats. The transformation induces large cyclic but reversible strains. The system response may be sensitive for the temperature range of the transformation relative the bond-coat yield strength [9]. Typical bondcoat yield strength and thermal strain is displayed in Fig. 2 $[14,15]$. In the simulations, the following values are used: $T_{2}=800{ }^{\circ} \mathrm{C}, M_{\mathrm{s}}=600{ }^{\circ} \mathrm{C}, A_{\mathrm{s}}=700^{\circ} \mathrm{C}, \Delta T_{\mathrm{m}}=100^{\circ} \mathrm{C}, \alpha_{\mathrm{B}_{2}}=$ $12.5 \times 10^{6}{ }^{\circ} \mathrm{C}^{-1}, \quad \alpha_{\mathrm{L}_{10}}=14.5 \times 10^{6}{ }^{\circ} \mathrm{C}^{-1}, E_{\mathrm{m}}=0.00635$. An axisymmetric FE-model is used, so to compare with the results obtained in [9].

The effect of thermal mismatch between bond-coat and substrate when the bond-coat undergoes martensitic transformation was discussed, but not explained, in [9]. The result indicated that the stresses in the top-coat were highest when $\alpha_{\mathrm{bc}}-\alpha_{\mathrm{sub}}<0$. This was not an expected result, since most thermal barrier systems have this type of mismatch. However, these results can now be explained based on the previous sections in the current paper (Figs. 19 and 20). The mismatch calculation in [9] was achieved by changing the thermal expansion of the substrate rather than the bond-coat, with the rational that the bond-coat properties are known from the experimental observations. However, we note that the case $\alpha_{\mathrm{bc}}-\alpha_{\text {sub }}<0$ (Figs. 19C and 20C) has the highest value for thermal expansion of the substrate. In the current paper, we have showed that the stresses and strain increase with increasing thermal expansion (e.g., Fig. 5). Thus, the results in Figs. 19 and 20, and corresponding results in [9] primarily are a consequence of the larger $\alpha_{\text {sub }}$. If we instead change the thermal expansion of the bond-coat to achieve the mismatch, the stresses and deformations become smaller for $\alpha_{\mathrm{bc}}-\alpha_{\mathrm{sub}}<0$ (not shown, for brevity). This concurs with the results for the cases without the martensitic transformations, e.g., Fig. 16.

The possibility of customizing the temperature range of the martensitic transformation in order to reduce the topcoat stresses and the morphology change in TBCs has often been raised. We investigate this in the following: by shifting the onset of martensitic transformation to higher and lower temperatures in the simulations, three scenarios are compared. The onset of transformation are assumed to occur at $M_{\mathrm{S}}=500^{\circ} \mathrm{C}$ and $A_{\mathrm{S}}=600^{\circ} \mathrm{C} ; M_{\mathrm{S}}=600^{\circ} \mathrm{C}$ and $A_{\mathrm{s}}=700^{\circ} \mathrm{C}$; and $M_{\mathrm{s}}=700^{\circ} \mathrm{C}$ and $A_{\mathrm{s}}=600^{\circ} \mathrm{C}$, respectively. The morphol- 
A $\alpha_{\mathrm{bc}}-\alpha_{\text {sub }}=2 \cdot 10^{-6} /{ }^{\circ} \mathrm{C}$

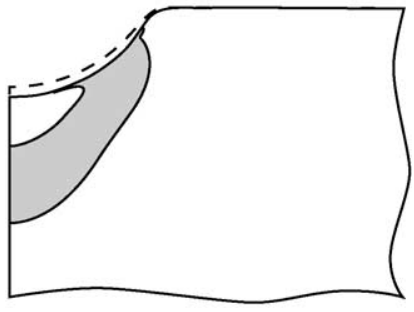

\begin{tabular}{|l|l|}
\hline B & $\alpha_{b c}-\alpha_{\text {sub }}=0$ \\
\hline
\end{tabular}

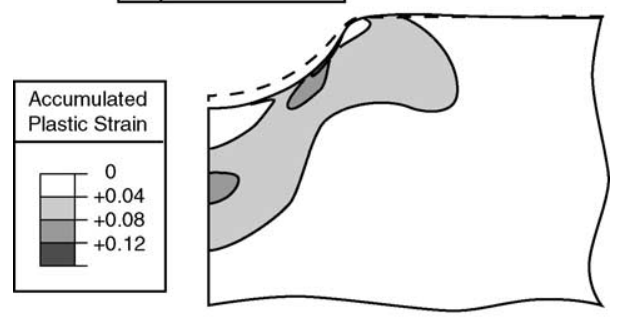

\begin{tabular}{|l|l|l}
$\mathrm{C}$ & $\alpha_{\mathrm{bc}}-\alpha_{\mathrm{sub}}=-2 \cdot 10^{-6} /{ }^{\circ} \mathrm{C}$ \\
\hline
\end{tabular}

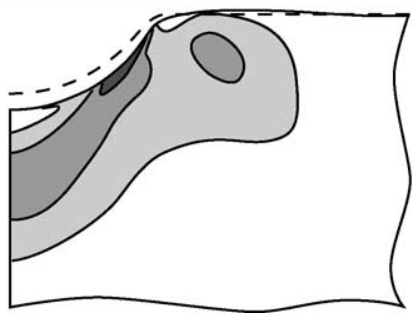

Fig. 19. Accumulated plastic strain after 24 cycles in the bondcoat for (A) $\alpha_{\mathrm{bc}}-\alpha_{\mathrm{sub}}=2 \times 10^{6}{ }^{\circ} \mathrm{C}^{-1}$, (B) $\alpha_{\mathrm{bc}}-\alpha_{\mathrm{sub}}=0$, and (C) $\alpha_{\mathrm{bc}}-\alpha_{\text {sub }}=-2 \times 10^{6}{ }^{\circ} \mathrm{C}^{-1}$. The difference refer to elevated temperatures, $T>T_{2}$, where for all cases $\alpha_{\mathrm{bc}}-\alpha_{\mathrm{B}}=12.5 \times 10^{6}{ }^{\circ} \mathrm{C}^{-1}$ and absent top cot.

ogy change (Fig. 21) increases drastically when the transformation occurs at higher temperature. This is so, since the bond-coat yield strength is lower at higher temperature, thus allowing for higher accumulation of plastic strain and thus larger deformation. However, when the top-coat is present, the crack opening stresses in the top-coat (Fig. 22) is not significantly changed. For this case, the constraint from the top-coat results in forward and reverse yielding being of the same magnitude in the bond-coat during cycling. Again, the stresses in the top-coat are mostly determined by the mismatch between substrate and top-coat. Thus, in summary, the results indicate that the development of morphological instabilities can be controlled by customizing the temperature range for the martensitic transformation, while the top-coat stresses are not affected.

\section{Concludingr emarks}

Numerical simulations utilizing the finite element method are conducted to investigate the intrinsic mismatch in thermal barrier systems prone to displacement instabilities of the
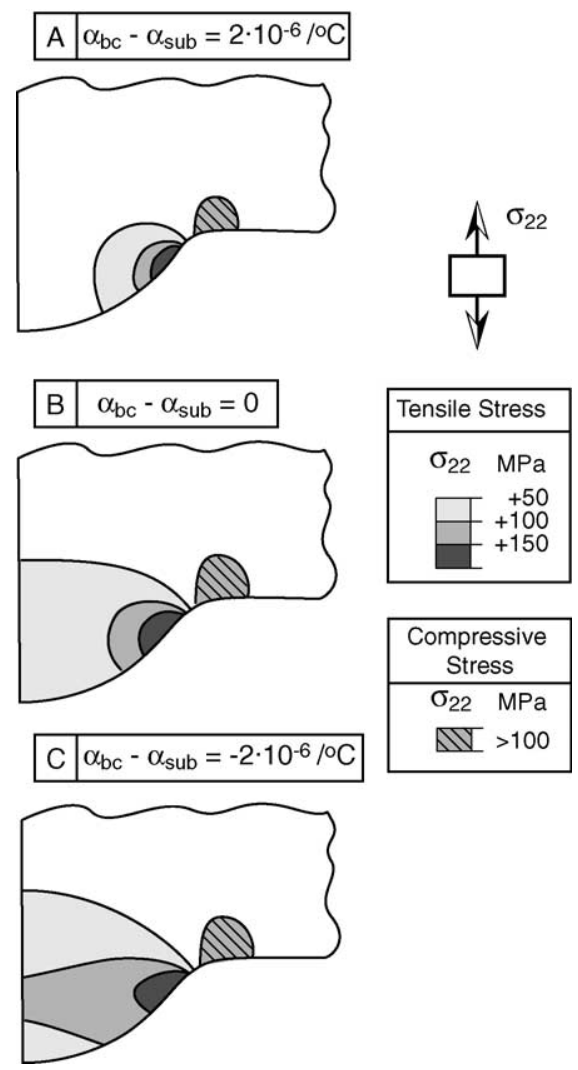

Fig. 20. The out-of-plane stresses in the top-coat after 24 cycles in the bond-coat for (A) $\alpha_{\mathrm{bc}}-\alpha_{\mathrm{sub}}=2 \times 10^{6}{ }^{\circ} \mathrm{C}^{-1}$, (B) $\alpha_{\mathrm{bc}}-\alpha_{\mathrm{sub}}=0$, and (C) $\alpha_{\mathrm{bc}}-\alpha_{\mathrm{sub}}=-2 \times 10^{6}{ }^{\circ} \mathrm{C}^{-1}$. The difference refer to elevated temperatures, $T>T_{2}$, where for all cases $\alpha_{\mathrm{bc}}-\alpha_{\mathrm{B}}=12.5 \times 10^{6^{\circ}} \mathrm{C}^{-1}$ is assumed.

TGO. Simulations with and without intact top-coat were conducted. The latter case corresponds to situations where large enough cracks between the top-coat and the TGO have developed, allowing the TGO to exhibit displacement instabilities. The effect of the bond-coat microstructure is incorporated, where the irreversible formation of $\gamma^{\prime}$-phase on the expense of $\beta$-grains are modeled, as well as the cyclic martensitic transformation.

The results show that the thermal expansion coefficient of the superalloy rules the behavior of the structure. The thermal expansion of the bond-coat only has a significant impact when the top-coat is not present. Thus, the morphological instabilities can be suppressed or enhanced by this mismatch.

A key parameter in these simulations is the high temperature yield and/or creep strength of the bond-coat. This paper confirms that morphological instabilities are suppressed for high enough yield strengths in the bond-coat.

The simulations indicate that it potentially could be possible to reduce the rate of the instability growth by designing the bond-coat so that the martensitic transformation occurs at a particular temperature range. However, this may be unrealistic since the onset of martensitic transformation may change depending on the level of aluminum in the bond-coat. Thus, the temperature range for the phase transformation may change with time. 

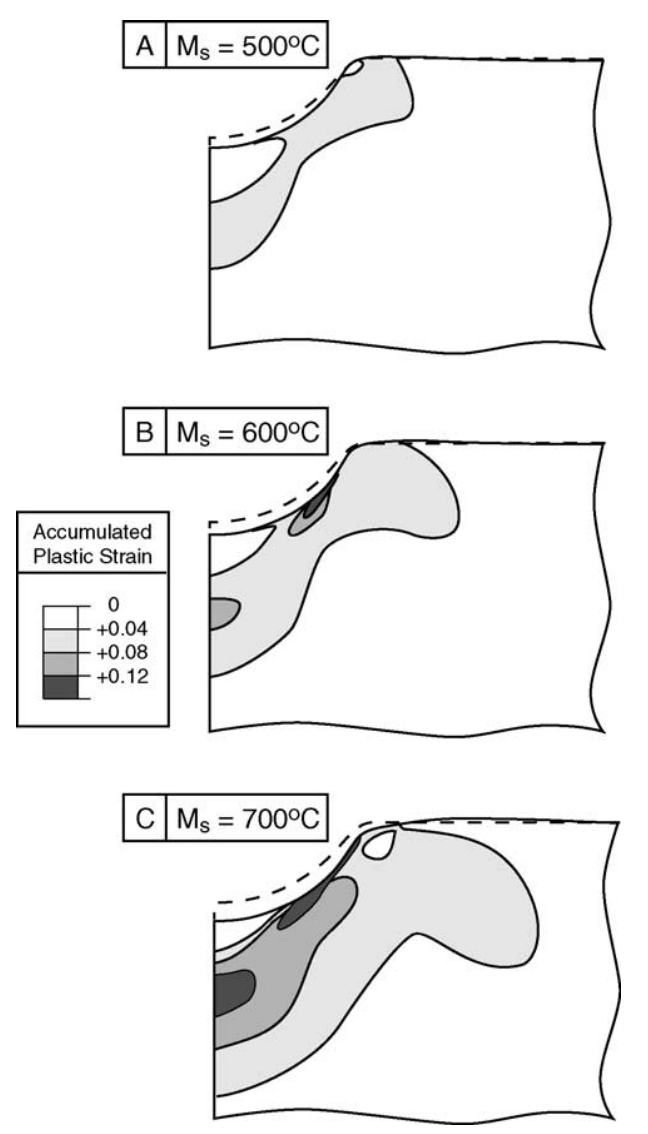

Fig. 21. Accumulated plastic strain after 24 cycles in the bond-coat for $M_{\mathrm{S}}=500^{\circ} \mathrm{C}(\mathrm{A}), 600^{\circ} \mathrm{C}(\mathrm{B})$, and $700^{\circ} \mathrm{C}(\mathrm{C})$. Absent top cot.

In all, the intrinsic mismatch in TBCs, in combination with the non-linear time and temperature dependent material properties, result in a complex response of the system.

\section{References}

[1] A.M. Karlsson, J.W. Hutchinson, A.G. Evans, Mater. Sci. Eng. AStruct. Mater. Prop. Microstruct. Process. 351 (2003) 244-257.

[2] X. Chen, J.W. Hutchinson, Int. J. Fract. 107 (2001) 31-51.

[3] A. Rabiei, A.G. Evans, Acta Mater. 48 (2000) 3963-3976.

[4] D.R. Mumm, A.G. Evans, I.T. Spitsberg, Acta Mater. 49 (2001) $2329-2340$.

[5] A.M. Karlsson, A.G. Evans, Acta Mater. 49 (2001) 1793-1804.

[6] A.M. Karlsson, J.W. Hutchinson, A.G. Evans, J. Mechanics Phys. Solids 50 (2002) 1565-1589.

[7] A.M. Karlsson, C.G. Levi, A.G. Evans, Acta Mater. 50 (2002) $1263-1273$.

[8] A.M. Karlsson, T. Xu, A.G. Evans, Acta Mater. 50 (2002) 1211-1218.

[9] A.M. Karlsson, J. Eng. Mater. Technol.-Trans. Asme 125 (2003) 346-352.

[10] S. Darzens, A. Karlsson, Surf. Coat. Technol. 177-178C (2004) $108-112$.

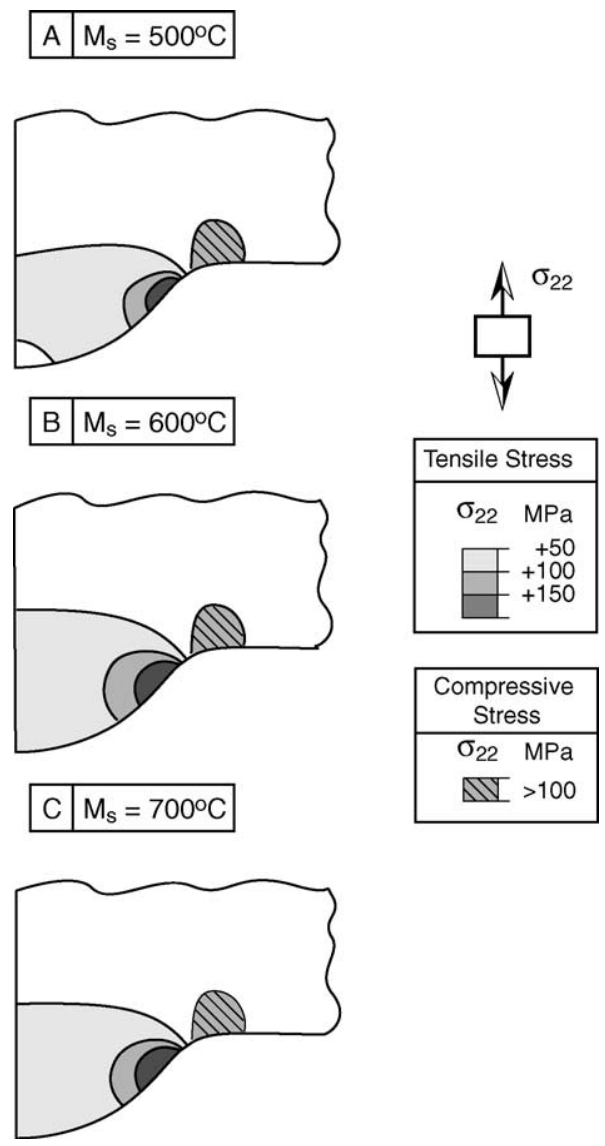

Fig. 22. The out-of-plane stresses in the top-coat after 24 cycles for $M_{\mathrm{s}}=500^{\circ} \mathrm{C}(\mathrm{A}), 600^{\circ} \mathrm{C}(\mathrm{B})$, and $700^{\circ} \mathrm{C}(\mathrm{C})$.

[11] M.Y. He, A.G. Evans, J.W. Hutchinson, Acta Mater. 48 (2000) 2593-2601.

[12] T. Tomimatsu, S. Zhu, Y. Kagawa, Acta Mater. 51 (2003) 2397-2405.

[13] J.A. Ruud, A. Bartz, M.P. Borom, C.A. Johnson, J. Am. Ceramic Soc. 84 (2001) 1545-1552.

[14] D. Pan, M.W. Chen, P.K. Wright, K.J. Hemker, Acta Mater. 51 (2003) 2205-2217.

[15] M.W. Chen, R. Ott, T.C. Hufnagel, P.K. Wright, K.J. Hemker, Surf. Coat. Technol. 163 (2003) 25-30.

[16] Y. Zhang, J.A. Haynes, B.A. Pint, I.G. Wright, W.Y. Lee, Surf. Coat. Technol. 163 (2003) 19-24.

[17] J.A. Haynes, B.A. Pint, W.D. Porter, I.G. Wright, Mater. High Temp. 21 (2004) 87-94.

[18] S. Rosen, J.A. Goebel, J. Less-Common Met. 16 (1968) 285.

[19] S. Darzens, D.R. Mumm, D.R. Clarke, A.G. Evans, Metall. Mater. Trans. A-Phys. Metall. Mater. Sci. 34 (2003) 511-522.

[20] J.A. Haynes, B.A. Pint, W.D. Porter, I.G. Wright, Mater. High Temp. 21 (2004) 87-94.

[21] ABAQUS 6.3 User's Manual, ABAQUS Inc., Pawtucket, Rhode Island, 2003.

[22] T. Xu, M.Y. He, A.G. Evans, Acta Mater. 51 (2003) 3807-3820.

[23] W. Xie, K.P. Walker, E.H. Jordan, M. Gell, J. Eng. Mater. Technol. 125 (2003) 200-207.

[24] T. Xu, M.Y. He, A.G. Evans, Interface Sci. 11 (2003) 349-358. 